\title{
Cadmium Level in Pregnancy, Influence on Neonatal Birth Weight and Possible Amelioration by Some Essential Trace Elements
}

\author{
Tawari Erebi $\mathbf{P}^{1 *}$, Anetor $\mathrm{JI}^{1}$ and Charles-davies $\mathrm{MA}^{2}$
}

${ }^{1}$ Department of Chemical Pathology, College of Medicine, University of Ibadan, Nigeria

${ }^{2}$ Department of Chemical Pathology, College of Medicine, University of Ibadan, Nigeria

\begin{abstract}
Cadmium is currently of great concern in rapidly industrializing countries- India, China. Their products consumed especially due to increased demand in many developing countries like Nigeria can result in adverse effects. Cadmium (Cd) is a ubiquitous environmental pollutant, toxicant and humans are continually exposed to the toxic effects of cadmium primarily through food as well as from environmental pollution through industrial activities. Maternal exposure to cadmium has been associated with the delivery of low birth weight babies and an increase incidence of spontaneous abortion. Cadmium a toxic metal can displace zinc (Zn) an essential element necessary for normal fetal development and growth. With this consideration, 160 subjects comprising of 125 pregnant and 35 non-pregnant subjects as controls were recruited for this study. The pregnant subjects were classified according to the three trimesters of pregnancy as followed; 35,35 and 55 from the first to the third trimesters respectively. The third trimester subjects were followed up until after delivery where neonatal parameters (birth weight, head circumference and length) of babies were measured. $32(58 \%)$ of the women delivered babies with normal birth weight, 19 women $(35 \%)$ delivered babies with low birth weight while 4 women $(7 \%)$ delivered babies with high birth weight. Subject who delivered low birth weight babies had significantly higher cadmium concentration and lower zinc concentration and Body Mass Index (BMI) when compared with those with normal weight babies. These results suggest that cadmium indeed has some toxic effects on neonatal birth weight.
\end{abstract}

Keywords: Cadmium; Zinc; Selenium; Birth weight

\section{Introduction}

Neonatal birth weight is one of the best markers of a favorable pregnancy outcome and determinant of prognosis of neonatal mortality and morbidity [1]. Most full term newborns (born at 37 and 40 weeks) weight between 2,812 grams and 4,173 grams. Babies weighing less than 2,500 grams are universally defined as low birth weight babies and are prone to health problems in the neonatal periods and in adulthood [2]. Many of the determinants of birth weight are related to maternal nutritional status [3] and the exposure to toxic pollutants such as cadmium, malnutrition and deficiency of some essential trace elements such as zinc, iron and copper may result in the delivery low birth weight babies [4].

Cadmium is a heavy metal posing severe risks to human health. Up to this day, it could not be shown that cadmium has any physiological function within the human body [5]. Exposure to cadmium is through ingestion of foods containing cadmium; low levels are found in all foods (highest levels are found in shellfish, liver, and kidney meats); smoking cigarettes or breathing cigarette smoke; breathing contaminated workplace air; drinking contaminated water; living near industrial facilities which release cadmium into the air [5]. Cadmium is more efficiently absorbed from the lungs than from the gastrointestinal tract [6].

Zinc is an essential trace mineral required by the body for a variety of fundamental biological functions. It plays major roles in the immune system, in reproduction, and in promoting healthy skin and growth. Zinc is required for normal fetal development and influences pregnancy outcome [7]. Maternal deficiency of zinc during pregnancy has been associated with the delivery of low birth weight babies [8,9]. Cadmium and zinc (both IIB transition elements) have similar electronic configuration and valence state, possessing equal affinities for sulphur, nitrogen and oxygen ligands [10] and hence similar geochemical and environmental properties [11]. They have an oxidative state of +2 and when ionized, are almost the same in size. Thus, cadmium can replace zinc in many biological systems. Cadmium has been described as an antimetabolite of Zinc due to the observed Zinc deficiency in most of the Cadmium-treated systems [12]. Cadmium toxicity is expressed in the body by zinc binding proteins particularly those containing zinc finger protein structures [13].

Data from animal studies suggest that maternal iron deficiency during pregnancy leads to lower birth weight and sustained blood pressure elevation in the offspring. In humans, iron deficiency during pregnancy is common and is associated with adverse birth outcomes such as low birth weight [14]. Iron deficiency can also enhance absorption of divalent metals such as lead, cadmium (Cd), aluminum (Al), and manganese (Mn) [15].

Selenium (Se) is a trace element required in small amounts, but can be toxic in larger amounts. It is necessary for growth and fertility in animals and for the prevention of accumulation of free radicals [16]. It also plays an important role in mitigating the biological damage caused by cadmium [17].

Copper $(\mathrm{Cu})$ is important for haemopoiesis and it is essential for normal growth and development of human fetuses, infants and children. Studies have shown that maternal deficiency of copper during pregnancy can result in the delivery of low birth weight babies [18].

The increasing implication of cadmium in the derangement of a number of biological and molecular systems especially genome instability or disturbances makes it instructive to examine the possible

*Corresponding author: Tawari Erebi P, Department of Chemical Pathology, College of Medicine, University of Ibadan, Nigeria, E-mail: perebi8@yahoo.com

Received March 16, 2012; Accepted April 13, 2012; Published April 18, 2012

Citation: Tawari EP, Anetor JI, Charles-davies MA (2012) Cadmium Level in Pregnancy, Influence on Neonatal Birth Weight and Possible Amelioration by Some Essential Trace Elements. Vitam Trace Elem 1:103.

Copyright: (C) 2012 Tawari EP, et al. This is an open-access article distributed under the terms of the Creative Commons Attribution License, which permits unrestricted use, distribution, and reproduction in any medium, provided the original author and source are credited. 
effects of cadmium where there are instinctive molecular events. This study was therefore conducted to examine the effect of cadmium on maternal and child health (neonatal birth weight) and evaluate the possible ameliorating effects of macro nutrients such as zinc, copper and selenium; particularly zinc which plays a pivotal role in the molecular process of reproduction, yet has been insufficiently heralded in the reproductive process.

\section{Materials and Methods}

A total of 160 subjects with age ranging from 18 to 45 years, with mean age of $20.1 \pm 6.1$ years comprising of 125 pregnant and 35 non-pregnant subjects as controls were recruited for this study from Antenatal Clinic of the Department of Obstetrics and Gynaecology University College Hospital (UCH) Ibadan and Oluyoro Catholic Hospital Oke Offa, Ibadan, Nigeria, after informed consents were obtained.

The pregnant subjects were classified according to the three trimesters of pregnancy as followed; thirty five (35), thirty five (35) and fifty five (55) from the first to the third trimesters respectively. The third trimester subjects were followed up until after delivery where neonatal parameters (birth weight, head circumference and length) of babies were measured. Head circumference was measured at the level of occipital protuberance and frontal. The body weight of each subject was measured with a standard scale to an accuracy of 0.1 gram.

Demographic characteristics of the subjects were obtained from the administration of a semi- structured questionnaire and anthropometric measurements- weight and height were measured while BMI was calculated. The neonates included in the study were all those who were delivered from participant mothers. The gestational age was measured in terms of weeks from the last menstrual period and accordingly an immature newborn was defined as a newborn with gestational age $<37$ weeks and a mature newborn as a newborn with gestational age $\geq 37$ weeks. Only babies born at full term were included in this study.

Subjects with HIV/AIDS, diabetes mellitus, pre-eclampsia, lactating women and those who did not give consent were excluded from the study.

Blood samples were collected and serum extracted for the measurement of Cadmium, Zinc, Iron, Selenium and Copper by atomic absorption spectrophotometry [19] while total protein and albumin were determined by Biuret method [20] using reagent kit by DIALAB Laboratory, United Kingdom and bromocresol green (BCG) method [21] using reagent kit produced by Span Diagnostics Limited respectively.

Data were analyzed statistically using SPSS version 15 to determine relationships and associations. Student t-test was used to find out significant differences between the means, one-way analysis of variance (ANOVA) used to investigate the statistical significance of the association between quantitative variables and Pearsons coefficients was used to find out associations between quantitative variables. Data are expressed as the mean $\pm S D$, and $p<0.05$ was considered statistically significant.

\section{Results}

Pregnant subjects had significantly lower $(\mathrm{p}<0.05)$ serum zinc, iron, and selenium levels as compared to non-pregnant subjects while serum copper level was found to be significantly elevated $(\mathrm{p}<0.05)$ (Table
1). Cadmium concentration was similar in all the groups except in the $3^{\text {rd }}$ trimester subjects where cadmium concentration was significantly higher when compared to the values obtained from the other subjects. Thirty five (35\%) of third trimester women delivered babies with low birth weight, fifty eight (58\%) with normal weight babies and seven (7\%) with high birth weight. Subjects who delivered low birth weight babies had significantly higher cadmium concentration, lower zinc concentration and body mass index (BMI) when compared with those subjects who delivered normal weight babies (Table 2). Babies low birth weight had lower neonatal parameters when compared with those normal birth weight (Table 3). Only maternal serum levels of cadmium, zinc and selenium correlated significantly with neonatal birth weight $\mathrm{p}<0.05$ (Table 4). Maternal serum cadmium $(\mathrm{r}=-0.708, \mathrm{p}$ $=0.000)$ and selenium $(r=-0.305, p=0.023)$ correlated negatively with birth weight were maternal zinc concentration $(r=0.306, p=0.023)$ correlated positively with birth weight.

\begin{tabular}{|l|l|l|l|l|l|l|}
\hline Parameter & $\begin{array}{l}\text { NP } \\
(\mathrm{n}=35)\end{array}$ & $\begin{array}{l}\text { 1st TRI } \\
(\mathrm{n}=35)\end{array}$ & $\begin{array}{l}\text { 2nd TRI } \\
(\mathrm{n}=35)\end{array}$ & $\begin{array}{l}\text { 3rd TRI } \\
(\mathrm{n}=55)\end{array}$ & F-value & p-value \\
\hline Cadmium( $\mu \mathrm{mol} / \mathrm{l})$ & $0.22 \pm 0.1$ & $0.20 \pm 0.1$ & $0.21 \pm 0.1$ & $0.25 \pm 0.2$ & 3.478 & $0.017^{*}$ \\
\hline Zinc $(\mu \mathrm{mol} / \mathrm{l})$ & $11.7 \pm 4.3$ & $11.4 \pm 2.9$ & $11.3 \pm 2.7$ & $10.4 \pm 2.4$ & 1.407 & $0.043^{*}$ \\
\hline Iron $(\mu \mathrm{mol} / \mathrm{l})$ & $26.9 \pm 6.5$ & $23.7 \pm 6.6$ & $25.9 \pm 6.2$ & $23.6 \pm 5.6$ & 2.742 & $0.045^{*}$ \\
\hline Copper( $\mu \mathrm{mol} / \mathrm{l})$ & $14.5 \pm 5.7$ & $14.9 \pm 3.3$ & $15.4 \pm 2.1$ & $16.8 \pm 3.6$ & 3.190 & $0.023^{*}$ \\
\hline Selenium( $\mu \mathrm{mol} / \mathrm{l})$ & $3.5 \pm 0.8$ & $3.4 \pm 0.7$ & $3.5 \pm 0.7$ & $3.4 \pm 0.8$ & 0.126 & 0.945 \\
\hline Total Protein(g/L) & $60.9 \pm 1.0$ & $64.0 \pm 0.9$ & $58.0 \pm 1.2$ & $63.0 \pm 1.2$ & 3.487 & $0.017^{*}$ \\
\hline Albumin(g/L) & $39.0 \pm 0.9$ & $35.0 \pm 0.7$ & $32.0 \pm 0.7$ & $33.0 \pm 0.8$ & 8.097 & $0.000^{*}$ \\
\hline Age(years) & $28.6 \pm 7.1$ & $28.6 \pm 5.7$ & $29.4 \pm 4.9$ & $29.5 \pm 6.5$ & 0.336 & 0.871 \\
\hline Parity & $2.0 \pm 1.6$ & $2.1 \pm 1.6$ & $1.9 \pm 1.7$ & $2.2 \pm 1.5$ & 0.236 & 0.671 \\
\hline BMl(kg/m2) & $25.3 \pm 3.6$ & $26.1 \pm 4.9$ & $27.6 \pm 5.4$ & $28.7 \pm 1.5$ & 0.997 & $0.039^{*}$ \\
\hline
\end{tabular}

"=significant at $\mathrm{p}<0.05$

$\mathrm{NP}=$ non-pregnant

$\mathrm{TRI}=$ Trimesters

$\mathrm{BMI}=$ body mass index

Table 1: Comparison of Demographic Indices, Anthropometric Measurements and Nutritional Parameters of Non-pregnant and Pregnant Subjects in $1^{\text {st }}, 2^{\text {nd }}$ and $3^{\text {rd }}$ Trimesters.

\begin{tabular}{|l|c|c|c|c|}
\hline Parameter & $\begin{array}{c}\text { Low birthweight } \\
(\mathrm{n}=19)\end{array}$ & $\begin{array}{c}\text { Normal birthweight } \\
(\mathrm{n}=32)\end{array}$ & $\mathrm{t}$-value & $\mathrm{p}$-value \\
\hline Cadmium $(\mu \mathrm{mol} / \mathrm{l})$ & $0.03 \pm 0.1$ & $0.02 \pm 0.1$ & 7.918 & $0.017^{*}$ \\
\hline Zinc $(\mu \mathrm{mol} / \mathrm{l})$ & $8.9 \pm 1.8$ & $11.2 \pm 2.3$ & 3.706 & $0.001^{*}$ \\
\hline Iron $(\mu \mathrm{mol} / \mathrm{l})$ & $22.6 \pm 4.9$ & $25.4 \pm 6.5$ & 1.784 & $0.08^{*}$ \\
\hline Copper $(\mu \mathrm{mol} / \mathrm{l})$ & $16.5 \pm 3.1$ & $16.9 \pm 3.7$ & 0.420 & 0.676 \\
\hline Selenium( $\mu \mathrm{mol} / \mathrm{l})$ & $3.5 \pm 0.7$ & $3.6 \pm 0.8$ & 1.628 & 0.109 \\
\hline Total Protein(g/L) & $69.0 \pm 1.54$ & $60.0 \pm 0.8$ & 2.756 & $0.008^{*}$ \\
\hline Albumin(g/L) & $32.9 \pm 0.6$ & $33.1 \pm 0.94$ & 0.088 & 0.930 \\
\hline Age $($ years $)$ & $28.68 \pm 7.5$ & $29.97 \pm 5.9$ & 0.487 & 0.701 \\
\hline Parity & $2.4 \pm 1.6$ & $2.1 \pm 1.5$ & 0.598 & 0.552 \\
\hline BMl $\left(\mathrm{kg} / \mathrm{m}^{2}\right)$ & $22.8 \pm 2.0$ & $28.8 \pm 4.1$ & 4.590 & $0.000^{*}$ \\
\hline
\end{tabular}

$=$ significant at $p<0.05$

$\mathrm{BMI}=$ Body mass index

Table 2: Third Trimester Maternal Indices of Women with Low and Normal Weight Babies.

\begin{tabular}{|l|c|c|c|c|}
\hline Parameters & $\begin{array}{c}\text { Normal birthweight } \\
(\mathrm{n}=32)\end{array}$ & $\begin{array}{c}\text { Low birthweight } \\
(\mathrm{n}=19)\end{array}$ & t-value & $\mathrm{p}$-value \\
\hline Birthweight $(\mathrm{kg})$ & $3.1 \pm 0.4$ & $2.2 \pm 0.3$ & 6.952 & $0.000^{*}$ \\
\hline Head circumference $(\mathrm{cm})$ & $34.6 \pm 3.8$ & $32.3 \pm 2.2$ & 2.675 & $0.010^{*}$ \\
\hline Length $(\mathrm{cm})$ & $50.1 \pm 3.6$ & $46.6 \pm 3.4$ & 3.818 & $0.000^{*}$ \\
\hline
\end{tabular}

*=significant at $p<0.05$

Table 3: Neonatal Anthropometric Measurements of Babies with Normal and Low Birthweight. 


\begin{tabular}{|l|l|l|l|}
\hline Maternal Indices & $\begin{array}{l}\text { Neonatal Birthweight }(\mathrm{kg}) \\
(\mathrm{r}, \mathrm{p} \text {-value }) \\
(\mathrm{n}=55)\end{array}$ & $\begin{array}{l}\text { Head } \\
\text { circumference }(\mathrm{cm}) \\
(\mathrm{r}, \mathrm{p} \text {-value }) \\
(\mathrm{n}=55)\end{array}$ & $\begin{array}{l}\text { Length }(\mathrm{cm}) \\
(\mathrm{r}, \mathrm{p} \text {-value }) \\
(\mathrm{n}=55)\end{array}$ \\
\hline Cadmium $(\mu \mathrm{mol} / \mathrm{l})$ & $-0.708,0000^{*}$ & $-0.332,0.013^{*}$ & $-0.499,0.001^{*}$ \\
\hline Zinc $(\mu \mathrm{mol} / \mathrm{l})$ & $0.306,0.023^{*}$ & $0.225,0.039^{*}$ & $0.247,0.036^{*}$ \\
\hline Iron $(\mu \mathrm{mol} / \mathrm{l})$ & $-0.192,0.160$ & $-0.161,0.241$ & $0.157,0.241$ \\
\hline Copper $(\mu \mathrm{mol} / \mathrm{l})$ & $0.022,0.872$ & $0.230,0.901$ & $0.066,0.634$ \\
\hline Selenium $(\mu \mathrm{mol} / \mathrm{l})$ & $-0.305,0.023^{*}$ & $-0.116,0.399$ & $-0.357,0.058$ \\
\hline BMI $\left(\mathrm{kg} / \mathrm{m}^{2}\right)$ & $0.781,0.000^{*}$ & $0.537,0.000^{*}$ & $0.488,0.000^{*}$ \\
\hline
\end{tabular}

* =significant at $\mathrm{p}<0.05$

$\mathrm{BMI}=$ Body mass index

Table 4: Correlation of Third Trimester Maternal Indices with Neonatal Parameters.

\section{Discussion}

Cadmium has recently emerged as an important public health environmental pollutant owing to its continuous release into the environment as a result of industrial activities particularly in the rapidly industrializing developing countries. Cadmium is listed as number 7 (out of 275) in the list of hazardous substances [6].

Many of the determinants of birth weight are related to maternal nutritional status [4]. Increased exposure to cadmium can create derangement in the levels of the micronutrients (zinc, selenium, copper and iron) which can have a deleterious effect on reproductive outcome [22].

In this study pregnancy outcomes (neonatal birth weight, head circumference and length) and nutritional indices (maternal zinc concentrations, weight and body mass index (BMI) were inversely and significantly correlated with cadmium concentration $(\mathrm{p}<0.05)$ in all cases. Neonatal head circumference and length were significantly lower in babies with low birth weight when compared with normal weight babies $(p<0.05)$. Cadmium concentrations in the women who delivered low birth weight babies were significantly higher than those with normal weight babies $(p<0.05)$. These observations suggest adverse effects of cadmium which are consistent with studies implicating cadmium as having toxic effects on neonatal growth $[23,24]$.

Serum copper concentrations increased progressively with advancement in pregnancy, with serum copper concentrations being highest in the third trimester. This finding is in agreement with previous observations [25]. However, there was no correlation between maternal copper concentrations and neonatal birth weight.

Subjects who delivered low birth weight babies had lower selenium concentrations when compared to subjects who delivered normal weight babies. There was a negative correlation between maternal selenium concentrations and neonatal birth weight. This inverse correlation may be as a result of the counteracting activity of selenium on cadmium toxicity suggesting that as cadmium level increased there was an increase in the activity of selenium probably due to oxidative stress induced by cadmium. This finding contradicts the observation that maternal selenium concentration had no impact on neonatal birth weight [26].

Zinc concentration in the $3^{\text {rd }}$ trimester subjects who delivered low birth weight babies were significantly lower than those with normal weight babies and a positive association was observed between maternal zinc status and neonatal parameters $(\mathrm{p}<0.05)$ which is in concordance with previous reports $[9,27]$.

The significant inverse correlation $(\mathrm{r}=-0.270, \mathrm{p}<0.05)$ observed between maternal cadmium and zinc concentrations suggests that as cadmium concentration increased there was a decline in maternal zinc concentration. This most probably accounted for the inadequate bioavailability of zinc required for many very fundamental biological activities such DNA and protein syntheses, bone metabolism associated with osteoblastic activities regulated by alkaline phosphatase which is dependent on zinc. This therefore, is largely the biochemical basis of the birth outcome observed in this study. The probable mechanism involved is that cadmium can displace zinc from metallothionenin, a binding protein that transports zinc since they both have similar configuration and almost the same size when ionized [13]. Thus in cadmium toxicity zinc is displaced from biological systems resulting in the adverse effects observed in this study.

\section{Conclusion}

Cadmium was found to have toxic effects on birth weight, head circumference and length of babies. The essential trace elements were significantly lower in women who delivered low birth weight babies and this suggests that environmental exposure to cadmium may have serious effect on the morbidity and mortality of neonates with long term health consequences. Therefore, it is recommended that environmental pollution be borne in mind particularly in regions with persistent low birth weight babies and supplements of essential trace micronutrients be given during pregnancy.

\section{References}

1. Bhargava M, Iyer PU, Kumar R, Ramji S, Kapani V, et al. (1991) Relationship of maternal serum ferritin with foetal serum ferritin, birth weight and gestation. J Trop Pediatr 37: 149-152

2. Barker DJ, Hales CN, Fall CH, Osmond C, Phipps K, et al. (1993) Type 2 (non-insulin dependent) diabetes mellitus, hypertension and hyperlipidemia (syndrome X): relation to reduced fetal growth. Diabetologia 36: 62-67.

3. Berghella $\vee$ (2007) Prevention of recurrent fetal growth restriction. Obstet Gynecol 110: 904-912.

4. Prentice AM (1991) Variation in maternal dietary intake, birth weight and breast milk output in the Gambia. In Maternal Nutrition during pregnancy and lactation, eds H Aebi and R.G Whitehead: 167-183.

5. Hogervorst J, Plusquin M, Vangronsveld J, Nawrot T, Cuypers A, et al. (2007) House dust as possible route of environmental exposure to cadmium and lead in the adult general population. Environ Res 103: 30-37.

6. Public health assessments completed (1999) Agency for Toxic substances and Disease Registry (ATSDR), Department of Health and Human Services (HHS) Notice. Fed Regist 64: 4422-4423.

7. Singh PP, Khushlani K, Veerwal PC, Gupta RC (1987) Materna Hypozincinaemia and low- birth-weight infants. Clin Chem 33: 1950.

8. Garg HK, Singhal KC, Arshad Z (1993) A study of the effect of oral zinc supplementation during pregnancy on pregnancy outcome. Indian $\mathrm{J}$ Physio Pharmacol 37: 276-284.

9. Goldenberg RL, Tamura T, Neggers Y, Copper RL, Johnston KE, et al. (1995) The effect of zinc supplementation on pregnancy outcome. JAMA 274: 463 468.

10. Nieboer E, Richaeddson DHS (1980) The replacement of the non-descriptive term"heavy metals" by a biologically and chemically significant classification of metal ions. Environmental Pollution Series B 1: 3-26.

11. Sorkun HC, Bir F, Akbulut M, Divrikli U, Erken G, et al. (2007) Toxicology 238 15-22.

12. Peraza MA, Fierro FA, Barber DS, Casarez, E, Rael LT (1998) Effects of micronutrients on metal toxicity. Environ Health Prespect 106: 203-216.

13. Berg JM (1990) Zinc fingers and other metal-binding domains. Elements for interactions between macromolecules. J Biol Chem 265: 6513-6516.

14. Milman N, Ibsen KK, Christensen JM (1987) Serum ferritin and iron status in mothers and newborn infants. Acta Obstet Gynecol Scand 66: 205-211.

15. Beard JL (2001) Iron biology in immune function, muscle metabolism and neuronal functioning. J Nutr 
Citation: Tawari EP, Anetor Jl, Charles-davies MA (2012) Cadmium Level in Pregnancy, Influence on Neonatal Birth Weight and Possible Amelioration by Some Essential Trace Elements. Vitam Trace Elem 1:103.

16. Silverman J, Katayama S, Zelenakas K, Lauber J, Musser TK, et al. (1981) Effect of retiniods on the induction of colon cancer in F344 rats by N-methyl-Nnitrosourea or by 1,2-dimethylhydrazine. Carcinogenesis 2: 1167-1172.

17. Bremner I (1978) Cadmium toxicity: Nutritional influences and the role of metallothionein. World Rev Nutr Diet 32: 165-197.

18. Krachler M, Rossipal E, Miceti-Turk D (1999) Trace element transfer from the mother to the newborn-- investigations on triplets of colostrum, maternal and umbilical cord sera. Eur J Clin Nutr 53: 486-494.

19. Fernandez FJ, Kahn L (1971) Graphite Atomic Absorption Spectrophotometry for metals. Atomic Absorption, News letter, 10:65.

20. Henry RJ, Cannon DC, Winkelman JW (1974). Clinical Chemistry: Principles and Techniques. Harper and Row Publishers, 2nd Ed.

21. Doumas BT, Watson WA, Biggs HG (1997) Albumin standards and the measurement of serum albumin with bromocresol green. Clin Chim Acta 258: 21-30.
22. Berghella V (2007) Prevention of recurrent fetal growth restriction. Obstet Gynecol 110: 904-912.

23. Shiverick KT, Salafia C (1999) Cigarette smoking and Pregnancy 1: ovarian, uterine and placental effects. Placenta 20: 265-272.

24. Nishijo M, Nakagawa H, Honda R, Tanabe K, Saito S, et al. (2002) Effects of maternal exposure to cadmium on pregnancy and breast milk. Occup Environ Med 59: 394-397.

25. Olatunbosun DA, Adadevoh BK, Adeniyi FA (1974) Serum copper in norma pregnancy in Nigerians. J Obstet Gynaecol Br Commonw 81: 475-478.

26. Mohammadzade A, Farhat AS, Valaee L, Khadem N, Khajedaluee M, et al. (2009) Maternal serum selenium and low birth weight neonates. J Neonata Perinatal Med 2: 103-107.

27. Hambidge KM, Krebs NF, Jacobs MA, Guyette L, Iklen DN, et al. (1983) Zinc nutritional status during pregnancy: a longitudinal study. Am J Clin Nutr 37 $429-442$. 